need to remain conscious of the risk of healthcare-associated infections.

We believe that strict adherence to standard and contact precautions can reduce the risk of nosocomial transmission of SFTSV and that taking airborne precautions as an extreme measure is required during aerosol-generating procedures. Additional evidence on the route of SFTSV transmission might guide the best precautions in the future.

Acknowledgements. We thank all the physicians and the staff at local public health centers and public health institutes who engage in surveillance activities in Japan.

Financial support. This report was funded by grants for the Research Program on Emerging and Re-emerging Infectious Diseases from the Japan Agency for Medical Research and Development.

Conflict of interest. All authors report no conflicts of interest relevant to this article.

\section{References}

1. Moon J, Lee H, Jeon JH, et al. Aerosol transmission of severe fever with thrombocytopenia syndrome virus during resuscitation. Infect Control Hosp Epidemiol 2019:238-241.
2. Siegel JD, Rhinehart E, Jackson M, Chiarello L. 2007 Guideline for isolation precautions: preventing transmission of infectious agents in health care settings. Am J Infect Control 2007;35:S65-S164.

3. World Health Organization. Personal protective equipment in the context of filovirus disease outbreak response: rapid advice guideline. World Health Organization website. https://apps.who.int/iris/handle/10665/ 251426. Published 2016. Accessed February 9, 2019.

4. Gai Z, Liang M, Zhang Y, et al. Person-to-person transmission of severe fever with thrombocytopenia syndrome bunyavirus through blood contact. Clin Infect Dis 2012;54:249-252.

5. Kim WY, Choi W, Park SW, et al. Nosocomial transmission of severe fever with thrombocytopenia syndrome in Korea. Clin Infect Dis 2015;60: 1681-1683.

6. Choi SJ, Park SW, Bae IG, et al. Severe fever with thrombocytopenia syndrome in South Korea, 2013-2015. PLoS Negl Trop Dis 2016;10: e0005264.

7. Shi J, Wang H, Huang D, et al. A cluster of symptomatic and asymptomatic infections of severe fever with thrombocytopenia syndrome caused by person-to-person transmission. Am J Trop Med Hyg 2017;97:396-402.

8. Gong Z, Gu S, Zhang Y, et al. Probable aerosol transmission of severe fever with thrombocytopenia syndrome virus in southeastern China. Clin Microbiol Infect 2015;21:1115-1120.

9. Jiang XL, Zhang S, Jiang M, et al. A cluster of person-to-person transmission cases caused by SFTS virus in Penglai, China. Clin Microbiol Infect 2015;21:274-279.

10. Severe fever with thrombocytopenia syndrome, Japan. Japanese National Institute of Infectious Diseases website. https://www.niid.go.jp/niid/ja/ sfts/3143-sfts.html [In Japanese.] Accessed February 9, 2019.

\title{
Practice and attitudes toward alcohol-based hand disinfection among German infection control teams
}

\author{
Sebastian Schulz-Stübner PD Dr. med. ${ }^{1}$, A Volkmann BA ${ }^{1}$, W Ebner Dr. med. ${ }^{2}$ and T Hauer Dr. med. ${ }^{1}$ \\ ${ }^{1}$ German Consulting Center for Infection Prevention and Control [Deutsches Beratungszentrum für Hygiene (BZH GmbH)], Freiburg, Germany and ${ }^{2}$ Institute for \\ Infection Prevention and Hospital Epidemiology, Medical Center, University of Freiburg, Freiburg, Germany
}

To the Editor-Recent publications have discussed the microbiological effectiveness of 15 seconds of alcohol-based hand disinfection and of reducing the time recommendations for alcohol-based hand disinfection in standard operating procedures to increase compliance, ${ }^{1}$ the reprocessing of conventional hand disinfection dispensers, ${ }^{2}$ and the technical failure rate of automatic hand disinfection dispensers, ${ }^{3}$ and the problems related to using alcoholcontaining tissue wipes rather than conventional dispensers. ${ }^{4}$

We designed an anonymous survey and distributed it during the 2018 Freiburg congress of infectious diseases and infection control (Freiburger Infektiologie- und Hygienekongress) to analyze the attitudes of German infection control teams regarding those issues and the integration of patients into hand disinfection programs.

\section{Material and Methods}

Congress participants were asked to deposit the filled out data sheets in exit-door drop boxes. Data were collected without personal

Author for correspondence: Dr Sebastian Schulz-Stübner, Email: Schulz-stuebner@bzhfreiburg.de

Cite this article: Schulz-Stübner S, et al. (2019). Practice and attitudes toward alcoholbased hand disinfection among German infection control teams. Infection Control \& Hospital Epidemiology, 40: 609-612, https://doi.org/10.1017/ice.2019.53 identifiers according to the EU General Data Protection Regulation (GDPR). Therefore this is not human research and the data analysis did not require the review of an institutional review board. Predefined subgroup analyses included nurse infection control practitioners (NICP) and physician members (PM) of the infection control team (either hygiene-link physicians or certified specialists in hospital hygiene). The Fisher exact test was used to test for significance between groups; $P<.05$ was considered statistically significant.

\section{Results}

In total, 385 surveys were returned (mean age, 50 years; range, 24-66). Of all respondents, $20 \%$ were from hospitals with $<200$ beds, $25 \%$ were from hospitals with $201-400$ beds, $18 \%$ were from hospitals with 401-600 beds, $19 \%$ were from hospitals with $>600$ beds, $13 \%$ were from rehabilitation hospitals, and $5 \%$ were from elsewhere ("other"). Among all respondents, 96 were in the PM group and 223 were in the NICP group; the remaining respondents were link nurses, public or occupational health physicians, and medical technicians. Table 1 shows the answers to the survey questions.

The only statistically significant difference $(P=.00001)$ between physician and nurse members of the infection control team was 
Table 1. Itemized Summary of Survey Items and Answers [translated from German]

\begin{tabular}{|c|c|c|c|}
\hline Survey Items and Answer Choices & $\operatorname{NICP}(n=223), \%$ & PM $(n=96), \%$ & All Respondents ( $n=385), \%$ \\
\hline 5 seconds & 0 & 0 & 0 \\
\hline 10 seconds & 0 & 1 & 1 \\
\hline 15 seconds & 15 & 10 & 13 \\
\hline 20 seconds & 4 & 8 & 5 \\
\hline 30 seconds & 79 & 80 & 79 \\
\hline No answer & 2 & 1 & 2 \\
\hline \multicolumn{4}{|c|}{ Question 2: In your opinion, how long is the real-life application time of alcohol-based skin disinfectants in daily practice? } \\
\hline 5 seconds & 11 & 24 & 15 \\
\hline 10 seconds & 38 & 34 & 38 \\
\hline 15 seconds & 39 & 33 & 36 \\
\hline 20 seconds & 9 & 7 & 8 \\
\hline 30 seconds & 2 & 2 & 2 \\
\hline No answer & 1 & 0 & 1 \\
\hline
\end{tabular}

Question 3: How much time is required for alcohol-based skin disinfection for routine use with the WHO 5 Moments of Hand Hygiene in your institution's standard operating procedures?

\begin{tabular}{lcccc}
\hline 15 seconds & 1 & 3 & 2 \\
\hline 30 seconds & 89 & 69 & 32 \\
\hline 60 seconds & 1 & 3 & 2 \\
\hline 90 seconds & 0 & 3 & 1 \\
\hline As specified by the manufacturer & 8 & 21 & 12 \\
\hline No answer & 1 & 1 & 1 \\
\hline
\end{tabular}

Question 4: How much time is required for surgical hand scrub with alcohol-based skin disinfectants in your institution's standard operating procedures?

\begin{tabular}{lccc}
\hline 30 seconds & 1 & 2 & 1 \\
\hline 60 seconds & 3 & 5 & 5 \\
\hline 90 seconds & 28 & 5 & 22 \\
\hline 3 minutes & 41 & 35 & 38 \\
\hline 5 minutes & 2 & 4 & 2 \\
\hline As specified by the manufacturer & 19 & 26 & 21 \\
\hline No answer & 6 & 23 & 11 \\
\hline
\end{tabular}

Question 5: What is your opinion regarding the following statement: "A shorter officially recommended application time of alcoholic hand disinfectants will increase the hand hygiene compliance"?

\begin{tabular}{lcccc}
\hline Agree & 8 & 20 & 12 \\
\hline Partially agree & 27 & 28 & 27 & 35 \\
\hline Partially disagree & 38 & 26 & 26 \\
\hline Disagree & 27 & 26 & 0 \\
\hline No answer & 0 & 0 & 0 \\
\hline
\end{tabular}

Question 6: What is your opinion regarding the following statement: "A realistic and doable time recommendation would increase the motivation to comply with that goal"?

\begin{tabular}{lccc}
\hline Agree & 23 & 41 & 29 \\
\hline Partially agree & 47 & 36 & 44 \\
\hline Partially disagree & 21 & 17 & 19 \\
\hline Disagree & 7 & 4 & 6 \\
\hline No answer & 2 & 2 & 2 \\
\hline & & & (Continued)
\end{tabular}


Table 1. (Continued)

Survey Items and Answer Choices

$\operatorname{NICP}(n=223), \%$

PM $(n=96), \%$

All Respondents ( $n=385)$, \%

Question 7: What is your opinion regarding the following statement: "You need an additional safety buffer regarding infection control recommendations because adherence with mandated times is always lower"?

\begin{tabular}{|c|c|c|c|}
\hline Agree & 27 & 23 & 25 \\
\hline Partially agree & 37 & 35 & 36 \\
\hline Partially disagree & 19 & 21 & 22 \\
\hline No answer & 1 & 1 & 1 \\
\hline \multicolumn{4}{|c|}{ Question 8: In your institution, is there a patient education program regarding alcohol-based hand disinfectant use? } \\
\hline No answer & 1 & 1 & 1 \\
\hline \multicolumn{4}{|c|}{ Question 9: In your institution, is there a "speak-up" campaign for patients regarding hand disinfection? } \\
\hline Yes & 18 & 20 & 18 \\
\hline No & 82 & 79 & 81 \\
\hline
\end{tabular}

Question 10: What is your opinion regarding the following statement: "Alcohol-containing tissues are a suitable alternative to pocket bottles for medical staff"?

\begin{tabular}{lrrr}
\hline Agree & 2 & 2 & 2 \\
\hline Partially agree & 4 & 5 & 5 \\
\hline Partially disagree & 28 & 35 & 30 \\
\hline Disagree & 65 & 56 & 61 \\
\hline No answer & 1 & 2 & 2 \\
\hline
\end{tabular}

Question 11: What is your opinion regarding the following statement: "Alcohol-containing tissues are suitable alternative to pocket bottles for patients"?

\begin{tabular}{lcccc} 
Agree & 6 & 2 & 5 \\
Partially agree & 26 & 21 & 25 \\
\hline Partially disagree & 24 & 29 & 25 \\
Disagree & 43 & 46 & 42 \\
No answer & 1 & 2 & 3
\end{tabular}

Question 12: What kinds of dispensers for alcohol-based hand disinfectants are used in your institution? (Multiple answers possible.)

$\begin{array}{lcccc}\text { Automated wall-mounted dispensers } & 22 & 21 & 21 \\ \text { Mechanical wall-mounted dispensers } & 38 & 37 & 37 \\ \text { Wall-mounted disposable pump dispensers } & 27 & 34 & 29 \\ \text { Bedrail-mounted disposable pump dispensers } & 13 & 8 & 12 \\ \text { No answer } & 0 & 0 & 1\end{array}$

Question 13: How often are dispensers for alcohol-based hand disinfectants cleaned and disinfected in your institution?

\begin{tabular}{lccc}
\hline Never & 17 & 11 & 39 \\
\hline If visibly soiled & 33 & 34 & 34 \\
\hline With each bottle change & 25 & 34 & 28 \\
\hline In fixed intervals & 24 & 12 & 20 \\
\hline No answer & 1 & 4 & 3 \\
\hline
\end{tabular}

Question 14: What is your opinion regarding the following statement: "It is mandatory that hand disinfectant dispensers can be use by elbow contact"?

\begin{tabular}{lcccc} 
Agree & 9 & 34 & 16 \\
Partially agree & 11 & 18 & 14 \\
\hline Partially disagree & 25 & 24 & 24 \\
Disagree & 54 & 23 & 43 \\
No answer & 1 & 1 & 3 \\
(Continued)
\end{tabular}


Table 1. (Continued)

\begin{tabular}{lccc}
\hline Survey Items and Answer Choices & NICP $(n=223), \%$ & PM $(n=96), \%$ & All Respondents $(n=385), \%$ \\
\hline Question 15: If you use automatic dispenser systems, how often do you observe service interruptions or technical defects? & 11 & 17 \\
\hline Common problem & 20 & 28 & 30 \\
\hline Rare problem & 32 & 3 & 4 \\
\hline No problem & 6 & 58 & 49 \\
\hline No answer & 42 & & 17 \\
\hline
\end{tabular}

Note. NICP, nurse infection control practitioner; PM, physician member of the hygiene team

${ }^{a} P=.00001$ (Fisher exact test) between NICP and PM, with "agree" and "partially agree" answers counted as "yes" answers and "partially disagree" and "disagree" answers counted as "no" answers for statistical analysis.

found regarding the need for using the elbow to activate the dispenser mechanism rather than touching the dispenser with undisinfected hands, which is favored by $52 \%$ of physicians compared to $20 \%$ of nurses (agree and partially agree answers were counted together, respectively). All other differences between the 2 professional groups were not significant.

\section{Discussion}

For most items, we did not find significant differences in the attitudes and preferences of physician and nurse members of the infection control team. Only elbow use of dispensers was significantly more important for physicians than for nurses, although there is no evidence for its practical value despite a theoretical rationale of less contamination of the dispenser itself.

Most infection control preventionists report that their institutional standard operating procedures define the time needed for hand disinfection as the 30 seconds indicated by the WHO Five Moments and still favor 30 seconds for alcohol-based hand disinfection. However, they acknowledge that in daily practice disinfection times of 30 seconds are almost never reached and that most disinfect their hands $<15$ seconds. However, most infection control preventionists think that a more realistic time requirement would increase the motivation of staff and overall adherence to hand hygiene policies, which is in accordance with the findings of Kramer et $\mathrm{al}^{1}$ in their observational study in a neonatal intensive care unit. The reported preference of 30 seconds but with an expectation of higher adherence with shorter times might be a sign of reluctance to change long-standing formal rules, which is a barrier in the conceptual frame of change management and implementation science. ${ }^{5}$ This theory is underscored by the fact that two-thirds of the respondents agreed with the statement that you need a buffer between the formal requirement in a standard operating procedure SOP and scientifically sound minimum to generate an additional safety corridor. Although this concept is often used to define technical safety limits, it can be deleterious in behavioral psychology because it undermines trust in the scientific base of infection control recommendations.

In most institutions patients are specifically targeted in hand hygiene programs, although $<20 \%$ of hospitals have a formal "speak up" campaign. Most survey respondents indicated that they would use alcohol-containing wipes as an alternative mode for hand disinfection for patients only and not for use by staff, and this idea is supported by the findings of Ory et al. ${ }^{4}$
The respondents described many different ways that alcoholbased hand disinfectant is provided in their respective institutions. Most described conventional wall-mounted dispensers, which leaves improvement potential for bedside-mounted systems that might better facilitate work flow. Technical problems with automatic systems seem to be a relevant issue, which supports the findings by Roth et al. ${ }^{2}$

We observed great variance in the way dispenser systems are cleaned and maintained: To do nothing, as reported by $15 \%$ of all respondents, is clearly unacceptable, whereas cleaning triggered by visual inspection is done by a weak majority and is supported by the literature. ${ }^{3}$

In summary, our survey indicated some improvement potentials regarding the infrastructure as well as the use of alcohol-based hand disinfection in German hospitals. We noted a certain amount of resistance by members of the infection control team irrespective of professional affiliation toward changing established formal practice patterns, despite new scientific evidence.

\section{Acknowledgments. None}

Financial support. This work was funded by institutional funds only.

Conflicts of interest. S.S.S. is shareholder of Deutsches Beratungszentrum für Hygiene (BZH GmbH) and receives royalties from Springer, Thieme, Deutsche Krankenhausverlagsgesellschaft and Consilium infectiorum. All authors report no conflicts of interest relevant to this article.

\section{References}

1. Kramer A, Pittet D, Klasinc R, et al. Shortening the application time of alcohol-based hand rubs to 15 seconds may improve the frequency of hand antisepsis actions in a neonatal intensive care unit. Infect Control Hosp Epidemiol 2017;38:1430-1434.

2. Roth JA, Batzer B, Hug BL, Widmer A. Defect rates in touchless versus mechanical hand hygiene dispensers. Infect Control Hosp Epidemiol 2018;39:359-360.

3. Schulz-Stübner S, Zimmer P, Leonards P, Schaumann R. Microbiological examination of hand disinfection dispenser pumps. Hygiene Med 2014;39:226-230.

4. Ory J, Zingg W, de Kraker MEA, et al. Wiping is inferior to rubbing: a note of caution for hand hygiene with alcohol based solutions. Infect Control Hosp Epidemiol 2018;39:332-335.

5. Clack L, Zingg W, Saint S, et al. Implementing infection prevention practices across European hospitals: an in-depth qualitative assessment. BMJ Qual Safety 2018;27:771-780. 